\title{
Unconnected body accrual of dietary lipid and protein in rats fed diets with different lipid and protein content.
}

\author{
Laia Oliva ${ }^{1}$, Tania Aranda ${ }^{1}$, Marià Alemany ${ }^{1,2,3}$, José-Antonio Fernández-López $z^{1,2,3}$, Xavier Remesar ${ }^{1,2,3^{*}}$ \\ ${ }^{1}$ Department of Biochemistry and Molecular Biomedicine, Faculty of Biology, University of Barcelona \\ ${ }^{2}$ Institute of Biomedicine (IBUB), University of Barcelona \\ ${ }^{3}$ CIBER OBN, Research Web, Barcelona
}

*Corresponding author

Prof. Xavier Remesar

Department of Biochemistry and Molecular Biomedicine

Faculty of Biology

University of Barcelona

Av. Diagonal 643

08028 Barcelona, Catalonia, Spain

e-mail: xremesar@ub.edu

Abbreviations:

SD: standard diet

CAF: cafeteria diet

HF: high-fat diet

HP: high-protein diet

Keywords: carbohydrate intake, dietary lipids, energy, protein accrual, rat 


\section{Abstract}

Scope: Eating large amounts of fat is usually associated with fat accumulation. However, different types of diets (not only lipids) elicit different metabolic responses.

Methods and results: Male and female rats (10wk-old) were distributed in four groups and fed for onemonth a standard diet (SD), or this diet enriched with either lipid (high-fat diet, HF) or protein (highprotein diet, HP), or a cafeteria diet (CAF). Both HF and CAF diets shared the percentage of energy from lipids (40\%) but these were different. Protein-derived energy in the HP diet was also 40\%. Feeding SD, HF and HP diets did not result in differences in energy intake, energy expenditure, total body weight or lipid content. However, the CAF fed groups showed increases in these parameters, which were more marked in the male rats. The CAF diet increased the mass of adipose tissue while the HF diet did not.

Conclusions: Different diets produced substantial changes in the fate of ingested nutrient energy. Dietary lipids were not essential for sustaining increases in body lipid (or adipose tissue) content. Body protein accrual was unrelated to dietary lipids and overall energy intake. Both protein and lipid accrual were more efficient in male than in female rats. 


\section{Introduction}

It is commonly assumed that accumulation of body fat correlates with excessive fat intake. ${ }^{[1]}$ Thus, diets laden with high energy contents have been widely used to obtain overweight or obese experimental animals. ${ }^{[2]}$ However, the abundance, diversity of purposes and lack of methodological uniformity of these diets often result in wide-ranging effects that cannot be explained solely by the age of the animals, ${ }^{[3]}$ the time course of the intervention, ${ }^{[4]}$ the energy density of the diets or their components, gender ${ }^{[5]}$ or even the palatability of the diet. ${ }^{[6]}$ As a consequence, the patterns of body weight increase are often unexplained and heterogeneous, including also a marked variability in the ratio of weight gain to lipid deposition. ${ }^{[7]}$ These effects have also been observed in humans. ${ }^{[8]} \mathrm{A}$ high-energy diet containing sufficient amounts of carbohydrate and protein facilitates the deposition of body fat, with dietary fat improving the palatability of most diets. Thus, fat and other appetite-eliciting flavours increase the hedonic response to food, both in humans ${ }^{[9]}$ and rats. ${ }^{[10]}$

Since high-fat diets have remarkable effects on body weight and metabolism ${ }^{[11]}$ and given that the mechanisms of nitrogen $(\mathrm{N})$ disposal are clearly linked to metabolic syndrome, ${ }^{[12]}$ these nutrients have been those most often studied. Their proportions in diets are assumed to strongly influence the fate of energy deposition. In many experiments performed on rodents, the additional dietary $\mathrm{N}$ load often consists of simply adding purified high-quality protein as an extra component, which alters dietary protein proportions and (obviously) the availability of many essential amino acids, as well as the way amino acids are disposed of ${ }^{[13]}$ when compared with their controls, often fed a quite different diet. Furthermore, the higher proportion of a synecdoche nutrient also affects energy density, as well as carbohydrate and lipid proportions. Thus, the evaluation of the results becomes complex, ${ }^{[14,15]}$ highlighting the need for multiple variants of diets and proportions to gain a minimum insight into the overall effects. Cafeteria diets are hyperlipidic ${ }^{[16]}$, but their protein content (and biological quality) is usually in the higher range of normalcy for rodents. ${ }^{[17]}$ This type of diets differs from the others described here, where only the protein or lipid component is modified and the rest of diet components maintain their relative interrelations as in the controls. In addition, the oligosaccharide (sucrose and lactose) and salt contents of most cafeteria diets are essential components to enhance their palatability. ${ }^{[10]}$ Dietary protein is critical for meeting the body's protein needs for growth and maintenance, with $\mathrm{N}$ homeostasis involving a powerful, finely tuned series of mechanisms that preserve body protein levels and their turnover. ${ }^{[18]}$ In standard diets for laboratory rodents, protein-derived energy accounts for about $20 \%$ of the total energy intake. Under normal metabolic conditions, increased protein availability enhances protein catabolism and lipid mobilisation, but also decreases food intake due to the satiating effect of proteins. ${ }^{[19]}$ When protein constitutes a large 
proportion of dietary energy, especially under conditions of low total energy availability such as during dieting, dietary protein is used in larger proportions as a source of energy, ${ }^{[20]}$ which results in a negative $\mathrm{N}$ balance, ${ }^{[21]}$ lower protein synthesis and even increased net body protein loss. ${ }^{[22]}$

The wide range of diets described in the literature, especially those differing in the relative proportions of their main energy supplies, is insufficient to establish the individual roles of nutrients in energy partitioning and fat deposition. Most of the data obtained using modified diets are usually based on the excessive intake of a specific nutrient/component; however, data on the effects of moderate changes in the relative proportion of macronutrients are scarce. It is important to compare different diets (standard vs. hyperlipidic for instance) that maintain maximal similarity in composition (and components), changing (as far as possible) only a specific component. It is commonly accepted that excess of dietary fat is essentially the key factor for fat accrual and excess energy intake, but there is a considerable amount of information that indicates that this factor is only another piece of the complex building of obesity and its accompanying pathologies. In the present study we wanted to expand a model we have developed previously to determine if that is true or not. Our key objective was to prove that not all high-fat highenergy diets are equal, and consequently do not affect fat accumulation in the same way. The use of highfat diets different from standard diets, not only on fat, but on almost everything else, only contributed to obscure the picture. Consequently, we wanted first to prove whether hyperlipidic diets are so fattening "only" because of their high fat/energy content. Our hypothesis is that other components, such as protein, or hedonic foods (and starchy carbohydrate by difference) play a critical role in the modulation of how this fat is used: accrual vs. oxidation.

\section{Experimental Section}

\subsection{Animals and experimental set up}

All animal handling procedures and the experimental setup were carried out in accordance with the animal handling guidelines of the European, Spanish and Catalan authorities. The Committee on Animal Experimentation of the University of Barcelona authorised the specific procedures used in the present study (\# DAAM 6911).

Ten-week-old male (initial weight, $364 \pm 12 \mathrm{~g}$ ) and female (initial weight, $233 \pm 8 \mathrm{~g}$ ) Wistar rats (Janvier, Le-Genest-Saint-Isle, France) were used ( $N=52)$. The animals were randomly divided into four groups ( $n=6-8$ in each group) for each sex, and were fed ad libitum for 30 days: rat chow (standard diet [SD], the SD group), a standard diet mixed with coconut oil (high-fat [HF] diet, the HF group), a simplified cafeteria diet [CAF] (the CAF group) or a standard diet mixed with proteins (high-protein [HP] diet, the HP group). All animals had free access to water. They were housed (in same-sex pairs) in solid-bottom cages with wooden shards as bedding material and were kept in a controlled environment (lights on from 08:00 
to $20: 00$, temperature $21.5-22.5^{\circ} \mathrm{C}$, and $50-60 \%$ humidity). Body weight and food consumption were recorded daily. The calculation of ingested food in rats fed the cafeteria diet was performed as previously described by weighing the differences in the food offered and the debris left, ${ }^{[16]}$ and correcting for dehydration.

\subsection{Diets}

The composition of the diets is shown in Table 1. The standard diet (Teklad 2014, Teklad diets, Madison, WI USA; which main ingredients were: wheat middlings, ground wheat, ground corn and corn gluten), contained $20 \%$ of digestible energy derived from proteins, $13 \%$ from lipids, and $67 \%$ from carbohydrates (including 10\% from oligosaccharides).

The HF diet was prepared by adding coconut oil to coarsely ground standard chow. The mixture, containing 33 parts (by weight) of standard chow, 4 parts of coconut oil and 16 parts of water, was thoroughly kneaded to form a rough paste, which was extruded using cut end syringes to form $1 \times 6-\mathrm{cm}$ cylindrical pellets that were dried at $40{ }^{\circ} \mathrm{C}$ for 24 hours. This diet contained $14 \%$ of digestible energy derived from proteins, $37 \%$ from lipids, and $49 \%$ from carbohydrates.

The simplified cafeteria diet was formed with standard chow pellets, plain cookies spread with liver pâté, bacon, water and milk, which was supplemented with $300 \mathrm{~g} / \mathrm{L}$ of sucrose and $30 \mathrm{~g} / \mathrm{L}$ of a mineral and vitamin supplement (Meritene, Nestlé, Esplugues, Spain). ${ }^{[23]}$ All components were kept fresh (i.e., renewed daily). From the analysis of the diet components and the ingested items, we calculated (from direct consumption measurements) that about $40 \%$ of the energy ingested was derived from lipids, $12 \%$ from proteins, and $48 \%$ from carbohydrates (of which $20 \%$ were from oligosaccharides).

The HP diet was obtained by adding casein and gelatine to a powdered standard chow. The mixture (16.5 g of standard chow $+2.35 \mathrm{~g}$ of casein $+2.05 \mathrm{~g}$ of gelatine $+0.2 \mathrm{ml}$ of sunflower oil $+17 \mathrm{ml}$ of water) was pelleted and dried at $40^{\circ} \mathrm{C}$ for 24 hours. When the pellets were analysed, we found that the energy derivable from proteins was $41 \%$, with $12 \%$ from lipids and $47 \%$ from carbohydrates.

The SD, HF and HP diets were administered in the form of dry extruded pellets. The CAF components were offered fresh daily and in excess in a small container. Aversion tests to the pellet diets were negative, i.e., there were no differences with the basic SD diet.

\subsection{Experimental design}

The animals were randomly distributed by sexes into the four dietary groups described above. After 30 days of the dietary treatment, the rats were anaesthetised with isoflurane at the beginning of the light cycle and blood was withdrawn with dry-heparinised syringes through the exposed aorta until exsanguination. Plasma was obtained by centrifugation and kept at $-20^{\circ} \mathrm{C}$ until analysis. White adipose 
tissue (WAT) from different locations, liver and interscapular brown adipose tissues were dissected and frozen in liquid nitrogen. The stomach and intestines were cleaned of their contents (which were discarded). These organs, the carcass and the remaining blood and other body debris were sealed in polyethylene bags, which were autoclaved at $120^{\circ} \mathrm{C}$ for $2 \mathrm{~h}$. The contents of these bags were weighed and then minced into a smooth paste with a blender (to obtain a 'total' rat homogenate), as previously described. ${ }^{[23]}$

\subsection{Analytical procedures}

The nitrogen, lipid and energy contents of the diet components were analysed. Nitrogen content was measured with the Kjeldahl procedure using the semi-automatic Pro-Nitro S system (JP Selecta, Abrera, Spain), whereas lipid content was measured using a solvent extraction method (trichloro methane/methanol, 2:1 v/v), as previously described. ${ }^{[24]}$ Total energy content was determined using a calorimetric bomb (C7000, Ika, Staufen, Germany). These procedures were also used for carcass lipid, protein and energy measurements. Benzoic acid standards were used for calibration.

\subsubsection{Fatty acid analyses}

Lipids from ground food samples were extracted overnight with the trichloro methane/methanol $(2: 1 \mathrm{v} / \mathrm{v})$ and processed for fatty acid analysis as previously described. ${ }^{[25]}$ Briefly, samples were suspended in $10 \%$ boron trifluoride (Fluka, Buchs, Switzerland) in methanol, and were stored in the dark at 4 으 for $12 \mathrm{~h}$. Hexane and water were added. After mixing, the whole organic phase was extracted, filtered and dried. The residue was dissolved in hexane (Panreac, Castellar del Vallès, Spain) and the samples were analysed with a CG-MS system (QP2010 Shimadzu, Kyoto, Japan), using a SP-2560 Supelco column (Supelco, Bellefonte, PA, USA). An extended methylated fatty acid mixture (Supelco FAME mix C4-C24) was used as the standard. Calculations were performed using the Shimadzu FASST for GC-MS software (version 2). Rates of recovery of lipids (and of fatty acid samples) were determined using internal standards of bis-C17:0 diacylglycerol (Sigma).

\subsection{Statistical analysis}

Energy intake was calculated from daily food consumption, which was converted using the energy equivalence of the different foods and components measured with the calorimeter bomb. Lean mass was calculated by subtracting lipid content from total weight. Lean mass increases were estimated using reference data from our previous studies using rats of the same stock, age and sex. ${ }^{[26,27]}$ Fat and protein intakes were calculated from total food intake, corrected for the respective protein or lipid content.

Statistical comparisons were performed using fixed-effect two-way ANOVA (sex, diet and their interaction) and post hoc Bonferroni tests, using the Prism 5.0 software (GraphPad Software Inc, La Jolla, 
CA, USA). Differences obtained with ANOVA or the Bonferroni test were considered statistically significant when the $p$ value was $<0.05$. Comparison between groups using Bonferroni's post-hoc test: differences between groups are represented by different superscript letters (capital letters for males, and low case for females).

Correlations between different parameters were determined by linear regression analysis using the same program, applying a $95 \%$ confidence interval and the value of the Pearson correlation coefficient.

\section{Results}

Table 1 shows the nutrient composition of the diets. The values for the CAF diet were obtained from actual consumption data and were close to those of the designed overall nutrient content. Both the crude and digestible energy contents were higher in the HF diet, since its energy content per $g$ was higher than those of the SD, HP and CAF diets. The CAF diet had the lowest crude energy value because of its low fibre content and high milk (i.e. high water) intake, although its digestible energy content was akin to that of the SD diet. Fat content was similar for the CAF and HF diets and was 3-fold higher than those of the SD and HP diets. The HP diet showed the highest proportion of proteins, whereas its lipid content was similar to that of the SD diet. The HF diet was the richest in C12:0+C14:0 fatty acids, followed by the CAF diet.

Energy intake, energy accrual and weight increase are shown in Figure 1. Marked differences between the dietary groups were found in all the analysed parameters. Groups fed the CAF diet showed the highest energy intake and energy accrual, as well as increases in weight and lean mass. Differences between the sex groups were also significant, with higher values for males; however, the energy cost of accrual was higher in females, with differences becoming significant for the HF and CAF groups.

Dietary treatment caused differences in (cleaned) gut weight, the values for all the female groups were significantly lower compared to their controls, whereas males showed lower values only for the HF diet (Table 2). Rats fed the CAF diet presented increased weights in WAT locations and in total WAT levels, whereas there were no differences for the HF groups with respect to controls. Liver weight showed no differences between the groups although its size was obviously higher in males than in females (their body weight was also greater). The HP diet did not significantly affect the weight of the other organs studied, except for interscapular brown adipose tissue, which had a significantly lower weight compared to those of rats on the SD diet (in both sexes), and for WAT from several locations in females.

Figure 2 shows the lipid intake, body lipid content and lipid balances among the different groups. The HF and CAF groups showed higher lipid intake and body lipid content than the SD group. However, only the females of the CAF group showed increases in relative lipid content, together with decreases in 
this parameter for the HP groups. The lipid balance values were highest in the CAF groups and presented the lowest values in the HP groups. The relative efficiency of direct lipid accretion was the highest in the SD groups, although males were more efficient than females in the HF and HP groups.

Figure 3 shows the data on protein intake. The HP and CAF groups showed the largest differences when compared to the SD group. However, the body protein content showed only slight differences between males, while there were no differences at all between the female groups. The extent of protein balance was markedly lower in the HF groups and in females fed the HP diet. As with lipids, protein accretion efficiency showed maximal values in the SD groups.

Energy and lipid accrual correlated (directly) with ingested energy, ingested lipid, and ingested carbohydrate levels (Figure 4) but did not correlate with ingested protein levels. Energy accrual also correlated inversely with fibre intake. Protein accrual only correlated (directly) with ingested protein and ingested carbohydrate and ingested fibre levels. We combined the data from the male and female rats to obtain these correlations in order to simplify the presentation, since the statistical significance of the correlations was the same when these populations were considered separately. Furthermore, the lipid content of animals correlates directly with the intake of lipids $(p<0.0001)$, carbohydrates $(p=0.0001)$ and energy $(p=0.0008)$, in a way similar to the correlations shown when compared with lipid accretion. On the contrary, there was no correlation with protein intake $(p=0.1779)$, and an inverse correlation with fiber intake $(p=0.0090)$.

\section{Discussion}

High-fat diets usually imply a potential increase in energy consumption and, consequently, elicit an increase in energy reserves that facilitates the development of obesity. ${ }^{[11,28,29]}$ This, depending on the duration of the dietary treatment, can be partly counterbalanced by an increase in satiation caused by the lipids themselves; ${ }^{[30]}$ and may also influence the extent of weight gain. ${ }^{[11,31]}$ In this work, the ingestion of a diet enriched with mainly saturated fats (coconut oil), containing a fat percentage ten times higher than that of the standard diet, did not cause per se an increase in the amount of energy ingested or significant variations in body weight (compared with controls fed the SD diet) during the period studied. This fact is consistent with previous data ${ }^{[32]}$ and might be explained in part by the presence of lauric acid, which has been found to decrease food intake. ${ }^{[33,34]}$ These results, however, contrast with the effects elicited by high-carbohydrate or cafeteria diets ${ }^{[35]}$ containing comparable proportions of energy derived from lipids, which have been reported to markedly increase weight, especially that of adipose tissue. Thus, these differences should be, mainly, a consequence of factors other than the type of fat used. It has been observed that palatability has notable effects on weight, especially if the contents of sucrose and salt are 
high, such as in cafeteria diets. ${ }^{[10]}$ Although these effects are similar in males and females, there is a higher cost of energy accrual in females on all diets, including the standard diet, which can be partly due to their different size, as previously described. ${ }^{[36]}$

The observed increase in white adipose mass in the CAF groups implies that the excess energy from lipid energy intake is partly used to increase inordinately the accumulation of fat. However, fat alone could not be the explanation, since the excess dietary fat was not stored in HF group, probably being oxidised for energy instead. ${ }^{[37]}$ These results show that a high-fat intake does not imply by itself a higher lipid balance. In fact, rats fed the standard diet were more efficient in managing dietary lipids for fat accretion when compared with the HF groups. Since a higher intake of saturated fatty acids has been associated with lower diet induced thermogenesis ${ }^{[38]}$ and given that coconut oil has been found not to increase the metabolic rate, ${ }^{[39]}$ we assume that the HF groups used the excess dietary fatty acids as a main source of energy, thus compensating for the relatively lower intake of carbohydrates of the SD group controls. In the CAF groups, however, excessive energy intake (lipid, carbohydrate and protein) allowed them to obtain more than enough energy to function, to increase thermogenesis ${ }^{\left[{ }^{[0]}\right.}$ and to increase both lean and adipose masses despite (or because of) their low efficiency of lipid accretion.

The effects of the high-protein diet on food intake, balances and energy accretion were limited and could only be attributed to the effect of protein per se, with possibly only a limited influence of the other macro-components of the diet. The results obtained with this diet indicated that a significant excess of protein (alone) was not enough to induce marked changes in body composition, especially with respect to lipid accretion. The satiating effect of protein ${ }^{[41]}$ did not seem to be enough to alter, for instance, total adipose weight. The cause of this apparent lack of effects may be a consequence of the relatively short treatment period (four weeks) used, as well as the nature of the protein used. ${ }^{[41]}$ This would be in line with the use, in humans, of high-protein diets for the treatment of obesity ${ }^{[42]}$ in contrast to the high obesogenic effect induced by cafeteria diets. Marked effects on body weight and composition can be detected after only two weeks of treatment using other dietary strategies and higher-protein contents. ${ }^{[43]}$ The tendency of the HP groups to lower their energy intake was confirmed by the decrease in the extent of lipid balance (although lean body mass was maintained), which resulted in a significantly lower lipid accretion efficiency in females. These tendencies, although not significant, together with the smaller size of fat depots are consistent, at least in females, with the widely described decreases in fat mass observed when high-protein diets are used. ${ }^{[4]]}$

The low protein balance observed in the HF groups, especially in males, did not seem to indicate protein deficiency, but equilibrium. The lack of changes (i.e. vs. SD controls) in both body weight and lean mass suggest that there was no protein deficiency, also proven by the high efficiency of their accretion. These results confirmed, albeit indirectly, that our high-fat diet (and the high-protein diet) ${ }^{[45]}$ allowed us 
to analyse the effects of the selected dietary macronutrient, with less interference coming from changes in the other components, thus minimising the effects of possible variations in diet composition and allowing for transversal comparisons.

If we assume that a large part of fat accretion corresponds mainly to deposited lipids in adipose tissue, ${ }^{[46]}$ the difference between the CAF and HF groups was extreme and cannot be explained by dietary lipids alone. Thus, lipid content per se could not be the main factor involved in energy partitioning (at least for fatty acids), indicating the involvement of other factors. There was a clear relationship between lipid and carbohydrate ingestion and energy accrual (largely lipid), whereas protein accrual did not depend either on energy or lipid intake. Thus, our results suggest that excessive energy might be used for adipose accrual, ${ }^{[4]}$ with other key factors, such as the composition of the lipids, amount of carbohydrates or palatability, ${ }^{[10]}$ strongly (further) affecting energy partitioning.

In spite of the inverse correlation between fibre content and energy accrual, we must consider that fibre does not interfere absorption, especially that of lipids, since lipid accretion efficiency (Figure 2) was higher for SD and HP diets, which show higher fibre content.

The fact that protein accumulation was only related to the intake of proteins and carbohydrates (but not to the overall intake of energy or lipids) needs further analysis and should be extended to humans. The results from the diets used here, which allowed us to differentiate the effects induced by different macronutrients (in rats), can have important consequences if extrapolated to humans. ${ }^{[48]}$ The habit of ingesting large amounts of high-quality protein in parallel to exercising does not seem to be the best way of increasing muscle mass, based on the data from this study (and overall real-life experience), although it has been recommended in humans. ${ }^{\left[{ }^{[9]}\right.}$ Perhaps, it may be more advisable to increase the intake of both proteins and carbohydrates in parallel to a decrease of lipid ingestion. The well-known obesogenic effects of short-chain carbohydrates ${ }^{[50]}$ also suggests that it is advisable to consume foods with a low glycaemic index. ${ }^{[51]}$ In summary, the natural mix of proteins, polysaccharides and fibre from many plant-based foods could achieve a balanced maintenance of lean body mass (i.e., muscle), avoiding the obesogenic effects of nutrient combinations in which the percentage of the different classes plays a critical role on energy partition, and taste tends to affect more the control of total energy intake. The interconnexion of both mechanisms often induces insufficiently sustained counsel on the selection of metabolically healthy diets.

In conclusion, the use of different diets with similar energy contents but varying lipid or protein contents (i.e. $40 \%$ of available energy as a maximum) substantially affected energy partitioning. Dietary lipids were not essential for sustaining increases in body lipid contents or adipose tissue masses. Protein accrual was dependent on protein intake and independent of lipid (and of overall energy) intake. Furthermore, in the present experimental set up, males were more efficient than females in both lipid and protein accrual. 


\section{Author contributions}

Conceptualisation: MA, XR and JAFL; data curation: LO and XR; formal analysis: JAFL; funding acquisition: XR; investigation: TA and LO; methodology: LO; validation: XR and JAFL; writing original draft: XR; writing and editing: LO, TA, MA, XR and JAFL.

\section{Acknowledgements}

We would like to thank the staff of the Scientific and Technological Centre of the University of Barcelona for analysing fatty acids.

\section{Conflict of interest}

The authors declare no conflict of interest.

\section{References}

[1] N. J. Rothwell, M. J. Stock, Clin. Endocrinol. Metab. 1984,13, 437.

[2] N. Hariri, L. Thibault, Nutr. Res. Rev. 2010, 23,270.

[3] A. Sclafani, A. N. Gorman, Physiol. Behav. 1977,18,1021.

[4] R. Schemmel, O. Mickelsen, Z. Tolgay, Am. J. Physiol. 1969, 216, 373.

[5] S. Agnelli, S. Arriarán, L. Oliva, X. Remesar, J. A. Fernández-López, M. Alemany, RSC Advances 2016, 6, 11278.

[6] L. Ghibaudi, J. C. Farley, M. van Heek, J. J. Hwa, Obes. Res. 2002, 10, 956.

[7] S. C. Woods, R. J., P. A., D. d'Alessio, P. Nutr. 2003, 133, 1081.

[8] L. Lissner, D. A. , B.J., H .J. Kalkwarf, D. A. Roe, Am. J. Clin. Nutr. 1987, 46, 886.

[9] C. Davis, N.J. Loxton, Nutrients 2014 6, 4338.

[10] L. Oliva,T. Aranda, G. Caviola, A.Fernández-Bernal, M. Alemany, J. A. Fernández-López, X. Remesar, PeerJ 2017, 5, e3697.

[11] R. Buettner, K. G. Parhofer, M. Woenckhaus, C. E. Wrede, L. A. Kunz-Schugart, J. Schölmerich, L.CBollheimer, J. Mol. Endocrinol. 2006, 15, 485.

[12] N. Zaragoza-Hermans, J. P. Felber, Horm. Metabol. Res. 1972, 4, 25.

[13] M. Lacroix, C. Gaudichon, A. Martin, C. Morens, V. Mathé, D. Tomé, J. F. Huneau , J.-F. Am. J. Physiol. 2004, 287, R934.

[14] J. A. Gilbert, A. Bendsen, A. Tremblay, A. Astrup, Nutr. Metab. Cardiovasc. Dis. 2011, 21, suppl.2B, 16.

[15] M. Cuenca-Sánchez, D. Navas-Carrillo, E. Orenes-Piñero, Adv. Nutr. 2015, 15, 260.

[16] E. Prats, M. Monfar, R. Iglesias, J. Castellà, M. Alemany, Physiol. Behav. 1989, 45, 263. 
[17] I. Rafecas, M. Esteve, J. A. Fernández-López, X. Remesar, M. Alemany, Mol. Cell. Biochem. 1993, 121, 45.

[18] M.Alemany, Nutr. Res. Rev. 2012, 25, 18.

[19] M.S. Westerterp-Plantenga, S.G. Lemmens, K.R. Westerterp, Br. J. Nutr. 2012, 108 (Suppl. 2), S105.

[20] L. Scalfi, F. Conlaldo, R. Borrelli, M. de Caterina, G. Spagnuolo, R. Alficri, M. Mancini, Ann. Nutr. Metab. 1987, 31, 154.

[21] J. S. Fisler, E. J. Drenick, D. E. Blumfield, M. E. Swendseid, Am. J.Clin. Nutr. 1982, 35, 471.

[22] S. Tsukahara, M. Ohno, Y. Ikeda, in: Diet and Obesity (Eds: G. A. Bray, J. LeBlanc, S. Inoue, M. Suzuki) Karger, Basel, Switzerland 1988, 205.

[23] M.Esteve, I.Rafecas, X. Remesar, M. Alemany, Int. J.Obesity 1992, 16, 237.

[24] J. Folch, M. Lees, G. H. Sloane-Stanley, J. Biol. Chem. 1957, 226, 497.

[25] X. Remesar, A. Antelo, C. Llivina, E. Albà, L. Berdié, S. Agnelli, S. Arriarán, J. A. Fernández-López, M. Alemany, PeerJ. 2015, 3, 1083.

[26] M.M. Romero, F. Holmgren, M.M. Grasa, M. Esteve, X. Remesar, J.A. Fernández-López, M. Alemany, PLoS One 2013, 8, e57342.

[27] M.M. Romero, S. Roy, K. Pouillot, M. Feito, M. Esteve, M. M. Grasa, J.A. Fernández-López, M. Alemany, X. Remesar, PLoS One 2014, 9, e90995.

[28] S. I. Martire, N. Holmes, R. F. Westbrook, M. J. Morris, PLoS One 2013, 8, e60407.

[29] P.J. Rogers, J.M. Brunstrom, Physiol. Behav. 2016, 164, 465.

[30] R. Buettner, J. Schölmerich, L. C. Bollheimer, Obesity 2007, 15, 798.

[31] R. Mariné-Casadó, C. Domenech-Coca, J.M. del Bas, C. Bladé, L. Arola, A. Caimari, Front. Phyiol. 2018, 9, 1639.

[32] N.M. Resende, H.R. Félix, M.R. Soré, A.M.M. Neto, K.E. Campos, G.T. Volpato, An. Acad. Bras. Ciênc. 2016, 88, 933.

[33] T. J. Little, K. L. Feltrin, M. Horowitz, A. J. P. M.Smout, T. Rades, J. H. Meyer, A. N. Pilichiewicz, J. Wishart, C .Feinle-Bisset, Am. J. Physiol. 2005, 289, R1090.

[34] T. Maher, M.E. Clegg, Crit. Rev. Food Sci. Nutr. 2019, 59, 1619.

[35] S. K. Panchal, H. Poudyal, A. Iyer, R. Nazer, A. Alam, V. Diwan, K. Kauter, C. Sernia, F. Campbell, L. Ward, G. Gobe, A. Fenning, L.Brown, J. Cardiovasc. Pharmacol. 2011, 57, 51.

[36] A. Valle, R. Guevara, F. J. García-Palmer, P. Roca, J. Oliver, Am. J. Physiol. 2007, 293, 1302.

[37] A. A. Papamandjaris, D. E. MacDougall, P. J. H. Jones, Life Sci. 1998, 62, 1203.

[38] H. Takeuchi, T. Matsuo, K. Tokuyama, Y. Shimomura, M. Suzuki, J. Nutr. 1995, 125, 920.

[39] F. X. Valente, F. G. Candido, L. L. Lopes, D. M. Dias, S. D. Carvalho, P. F. Pereira, J. Bressan, Eur. J. Nutr. 2018, 57, 1627.

[40] N.J. Rothwell, M.J. Stock, B.P. Warwick, Metabolism 1985, 34, 474. 
[41] J. Zhou, M. J. Keenan, J. N. Losso, A. M. Raggio, L. Shen, K. L. McCutcheon, R. T. Tulley, M. R. Blackman, R. J. Martin, Obesity 2011, 19, 1568.

[42] A.Makris, G.D.Foster, Psychiatr. Clin North Am., 2011, 34, 813.

[43] A. Stengel, M. Goebel-Stengel, L. Wang, E. Hu, H. Karasawa, J. R. Pisegna, Y. Taché, Am. J. Physiol. 2013, 305, R582.

[44] D. Tomé, C. Chaumontet, P. C. Even, N. Darcel, D. Azzout-Marniche, Physiol. Behav. 2019, 206, 7.

[45] L. Oliva, M. Alemany, X. Remesar, J. A. Fernández-López, Nutrients 2019, 11, 316.

[46] P.G. Blanchard, W. T. Festuccia, V. P. Houde, P. St-Pierre, S. Brûlé, V. Turcotte, M. Côté, K. Bellmann, A. Marette, Y. Deshaies, J. Lipid Res. 2012, 53, 1117.

[47] P.A. Kakimoto, A.J. Kowaltowski, Redox Biol. 2016, 8, 216.

[48] S.M. Pasiakos, J. Food Sci. 2015, 80 (suppl 1), A2.

[49] N. E. Deutz, J. M. Bauer, R. Barazzoni, G. Biolo, Y. Boirie, A. Bosy-Westphal, T. Cederholm, A. CruzJentoft, Z. Krznariç, K. S. Nair, P. Singer, D. Teta, K. Tipton, P. C. Calder, Clin. Nutr. 2014, 33, 929.

[50] O. E. Michaelis, B. Szepesi, Nutr. Metab. 1977, 21, 329.

[51] J. Wylie-Rosett, C. J. Segal-Isaacson, A. Segal-Isaacson, Obes. Res. 2004, 12, $124 \mathrm{~S}$.

\section{Figure legends}

Figure 1. Energy intake, energy accrual and weight increase. Data are the mean \pm SEM of six to eight animals per group.

White bars: standard diet (SD); black bars: high-fat diet (HF); dashed bars: cafeteria diet (CAF); and lattice bars: high-protein diet (HP). Statistical differences between groups: two-way ANOVA (D, diet; S, sex; I, their interaction). Only the significant values are shown. Bonferroni post-hoc test: different letters represent statistically significant differences between groups of the same sex.

Figure 2. Lipid intake, body lipid content and lipid balance. Data are the mean \pm SEM of six to eight animals per group.

White bars: standard diet (SD); black bars: high-fat diet (HF); dashed bars: cafeteria diet (CAF); and lattice bars: high-protein diet (HP). Statistical differences between groups: two-way ANOVA (D, diet; S, sex; I, their interaction). Only the significant values are shown. Bonferroni post-hoc test: different letters represent statistically significant differences between groups of the same sex.

Figure 3. Protein intake, body protein content and protein balance. Data are the mean \pm SEM of six to eight animals per group.

White bars: standard diet (SD); black bars: high-fat diet (HF); dashed bars: cafeteria diet (CAF); and lattice bars: high-protein diet (HP). Statistical differences between groups: two-way ANOVA (D, diet; S, sex; I, their interaction). Only the significant values are shown. Bonferroni post-hoc test: different letters represent statistically significant differences between groups of the same sex.

Figure 4. Relationships between energy, lipid or protein accrual and energy, lipid, protein or carbohydrate intake. Relationships between total fibre intake and energy or protein accrual. 
Table 1. Diet composition and diet components

\begin{tabular}{|c|c|c|c|c|}
\hline & $\begin{array}{l}\text { Standard } \\
\text { diet (SD) }\end{array}$ & $\begin{array}{l}\text { High-fat diet } \\
\text { (HF) }\end{array}$ & $\begin{array}{l}\text { Cafeteria } \\
\text { diet* (CAF) }\end{array}$ & $\begin{array}{l}\text { High-protein } \\
\text { diet (HP) }\end{array}$ \\
\hline Crude energy content (kJ/g) & 16.5 & 18.8 & $12.4 \pm 0.2$ & 17.4 \\
\hline Digestible energy content $(\mathrm{kJ} / \mathrm{g})$ & 12.1 & 14.6 & $12.0 \pm 0.1$ & 12.4 \\
\hline \multicolumn{5}{|l|}{ Gross Composition (\%) } \\
\hline Protein & 14.3 & 11.6 & $7.96 \pm 0.4$ & 28.7 \\
\hline Lipid & 4.0 & 13.4 & $11.6 \pm 0.9$ & 3.89 \\
\hline Carbohydrate & 48.0 & 39.1 & $31.7 \pm 0.5$ & 33.7 \\
\hline Fibre & 18.0 & 14.6 & $2.79 \pm 0.2$ & 12.9 \\
\hline Ashes & 4.70 & 3.82 & $2.79 \pm 0.1$ & 3.30 \\
\hline Moisture & 6.90 & 12.4 & $47.2 \pm 1.2$ & 12.3 \\
\hline \multicolumn{5}{|l|}{ Food components of diet (g/kg) } \\
\hline Chow pellet & 1000 & 901 & $113 \pm 8$ & 804 \\
\hline Coconut oil & & 99 & & \\
\hline Gelatine & & & & 100 \\
\hline Casein & & & & 87 \\
\hline Bacon & & & $123 \pm 1.1$ & \\
\hline Cookies (plain) & & & $209 \pm 15$ & \\
\hline Liver Paté & & & $126 \pm 13$ & \\
\hline Cow's milk (full-fat) & & & $335 \pm 25$ & \\
\hline Sunflower oil & & & & 9 \\
\hline Sucrose & & & $101 \pm 12$ & \\
\hline \multicolumn{5}{|l|}{$\%$ energy derived from nutrients } \\
\hline Protein & 19.3 & 14.5 & $11.7 \pm 0.4$ & 40.4 \\
\hline Lipid & 12.5 & 36.8 & $39.5 \pm 0.9$ & 11.6 \\
\hline Carbohydrate & 67.1 & 48.6 & $48.5 \pm 0.5$ & 47.7 \\
\hline Sugars (as \% of carbohydrate) & $<1$ & $<1$ & $24.1 \pm 0.5$ & $<1$ \\
\hline Lipid/Protein ratio & 0.625 & 2.53 & $3.39 \pm 0.2$ & \\
\hline \multirow{2}{*}{\multicolumn{5}{|c|}{ Mean Fatty acid content (\% of total) }} \\
\hline & & & & \\
\hline Saturated & 25 & 74 & 55 & 25 \\
\hline$C 12: 0+C 14: 0$ & 2 & 53 & 22 & 2 \\
\hline Monounsaturated & 14 & 19 & 35 & 14 \\
\hline C18:1 & 13 & 19 & 33 & 13 \\
\hline Polyunsaturated & 61 & 5 & 12 & 61 \\
\hline C18:2 & 56 & 56 & 11 & 55 \\
\hline
\end{tabular}

*Data obtained from the food consumption data of the animals fed cafeteria diet (mean male values). Intake differences between male and female animals were not statistically significant. 

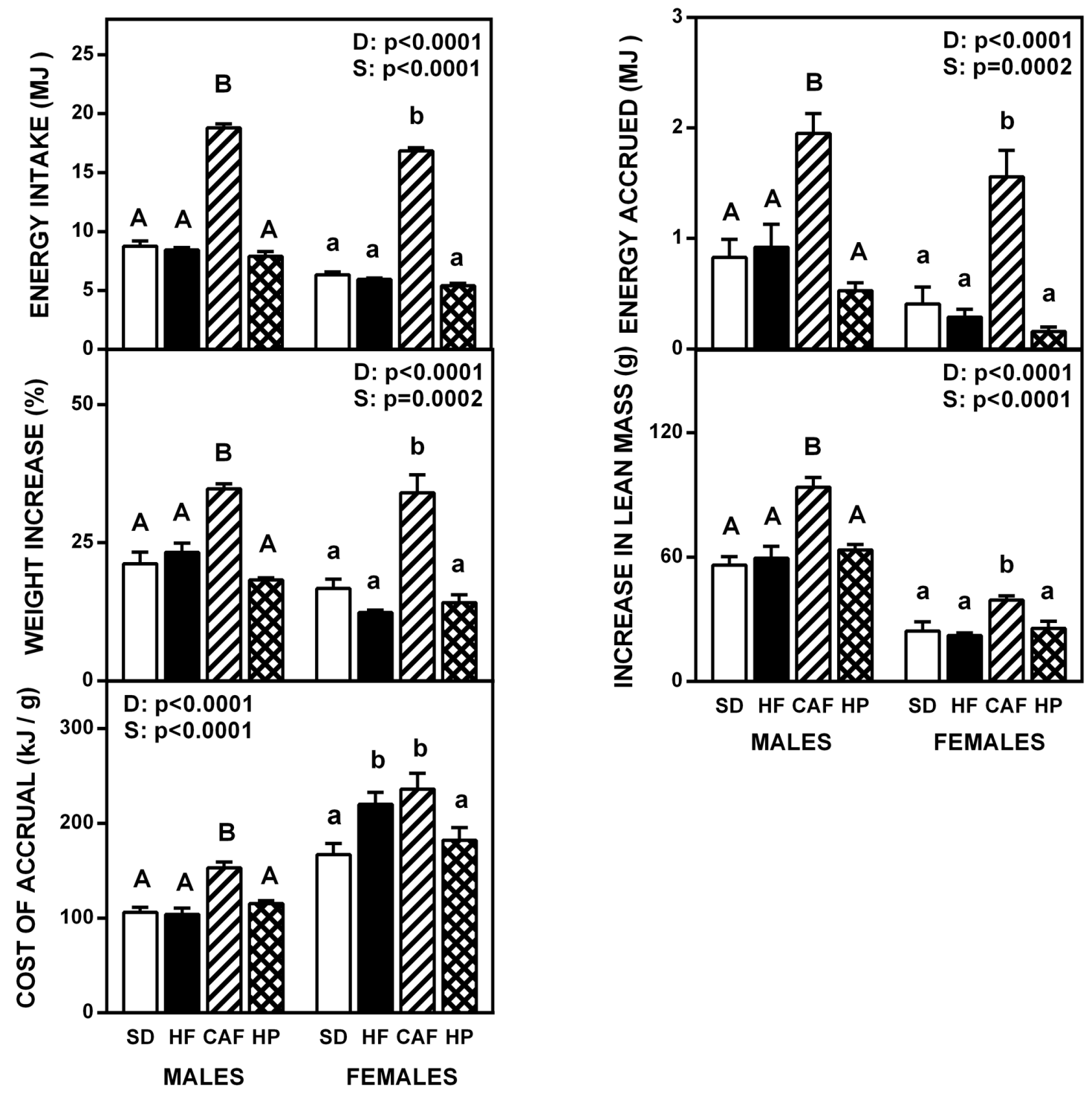

FIGURE 1 

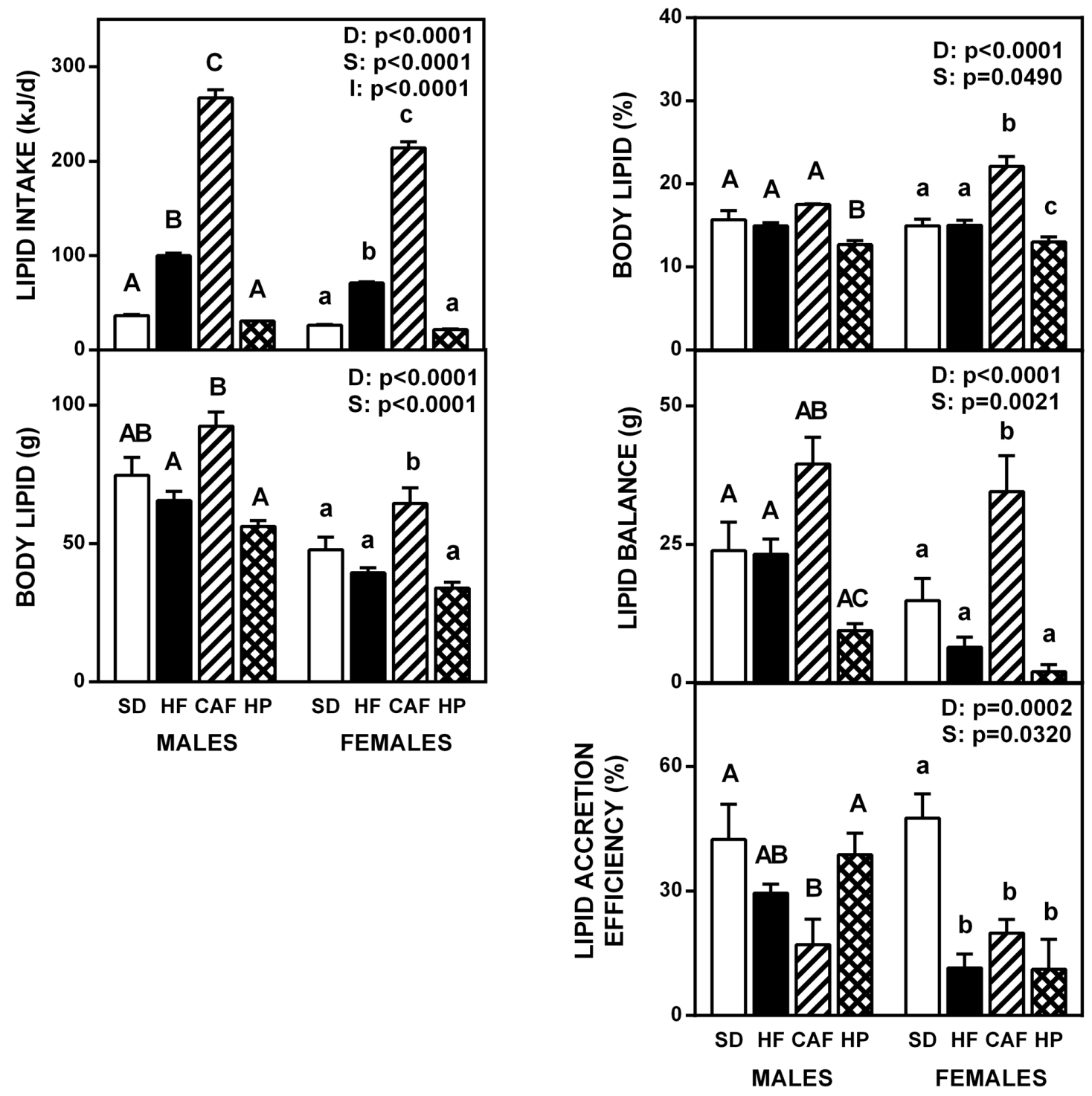

FIGURE 2 

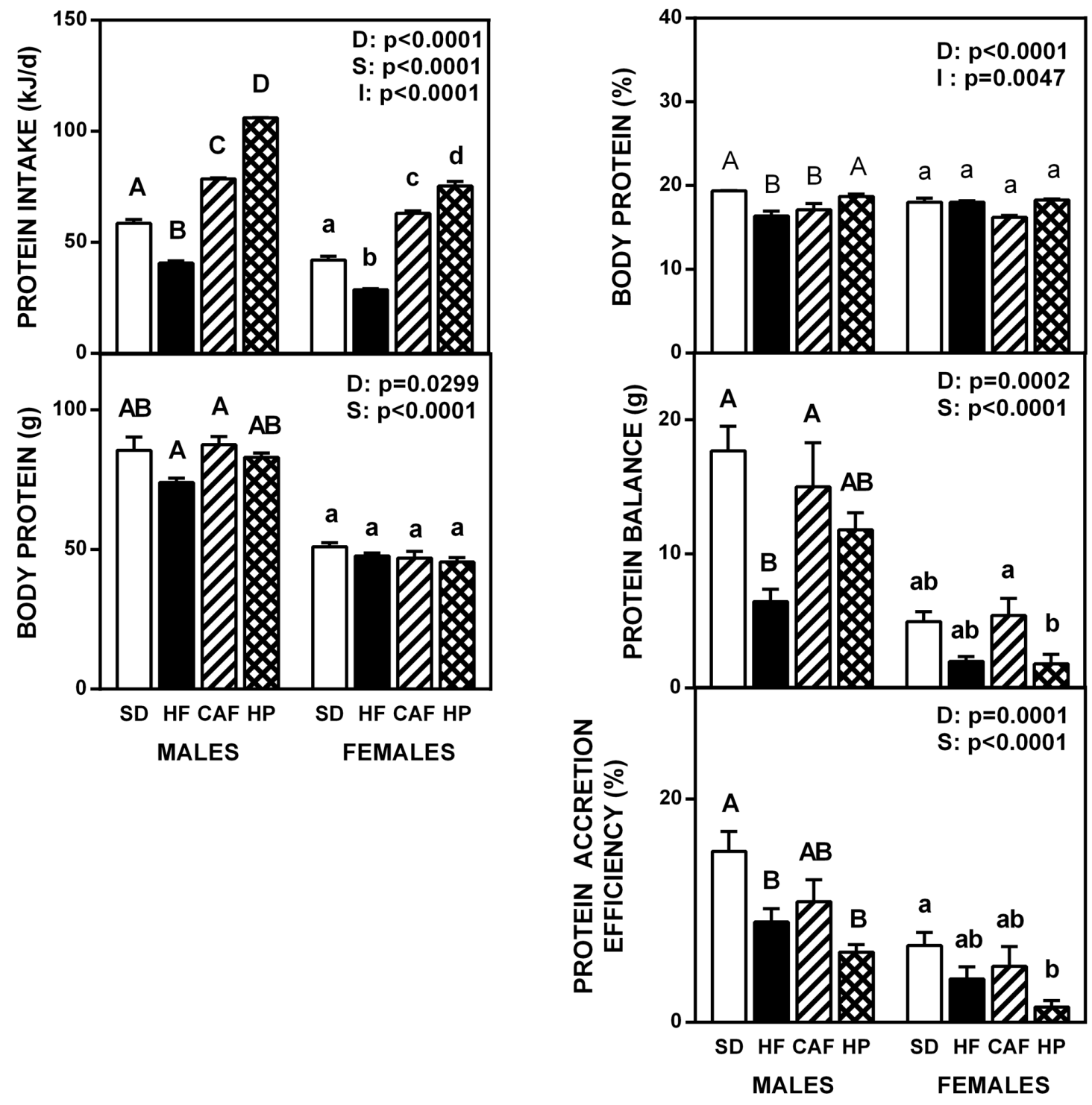

FIGURE 3 

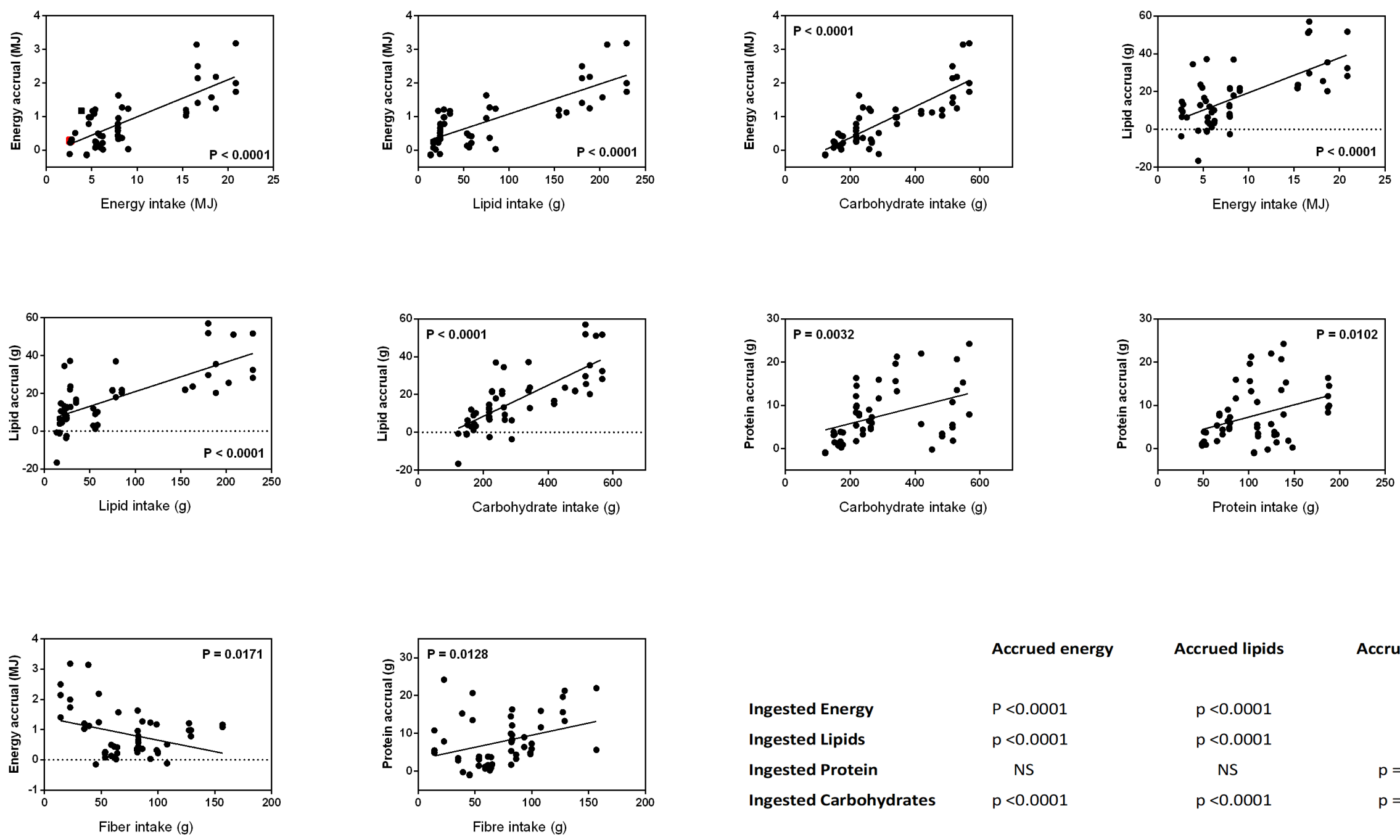

Accrued energy

$P<0.0001$
$p<0.0001$
NS
$p<0.0001$

Ingested Carbohydrates
Accrued lipids

$\mathrm{p}<0.0001$

$\mathrm{p}<0.0001$

NS

$p<0.0001$
Accrued protein

NS

NS

$p=0.0102$

$p=0.0020$

FIGURE 4 
Table 2. Weight (absolute and relative) of different tissues after dietary treatment.

organ units

\begin{tabular}{llllll}
\cline { 3 - 5 } Liver & & gD diet & HF diet & CAF diet & HP diet \\
& \% b.w. & $3.71 \pm 0.16^{A}$ & $3.02 \pm 0.05^{B}$ & $3.54 \pm 0.03^{A}$ & $3.41 \pm 0.08^{A B}$ \\
Gut & $g$ & $6.84 \pm 0.7^{A}$ & $4.97 \pm 0.3^{\mathrm{B}}$ & $6.34 \pm 0.2^{\mathrm{A}}$ & $6.91 \pm 0.3^{\mathrm{A}}$ \\
& \% b.w. & $1.62 \pm 0.07$ & $1.14 \pm 0.08^{\mathrm{B}}$ & $1.35 \pm 0.04^{A B}$ & $1.56 \pm 0.05^{A}$
\end{tabular}

Adipose Tissue: White: (perigonadal PG, retroperitoneal RP, mesenteric ME, total WAT); Brown (interscapular BAT)

RP-g

g $\quad 7.88 \pm 0.74^{\AA}$

\% b.w. $1.86 \pm 0.10^{A}$

$6.28 \pm 0.42^{\mathrm{A}}$

\begin{abstract}
$11.1 \pm 0.5^{\mathrm{B}}$
\end{abstract}
$2.36 \pm 0.05^{A C}$

$6.96 \pm 0.7^{\mathrm{A}}$

$1.57 \pm 0.15^{A}$

$7.36 \pm 0.7^{\mathrm{A}}$

$7.47 \pm 0.64^{\mathrm{A}}$

$12.6 \pm 1.0^{\mathrm{B}}$

$2.69 \pm 0.19^{A C}$

$1.65 \pm 0.15^{A}$

$7.19 \pm 0.11^{\mathrm{B}}$

$5.03 \pm 0.4^{\mathrm{A}}$

$5.75 \pm 0.35^{\mathrm{AB}}$

$1.54 \pm 0.08^{A}$

$1.13 \pm 0.08^{A}$

$30.9 \pm 1.3^{\mathrm{B}}$

$19.4 \pm 1.7^{\mathrm{A}}$

$19.5 \pm 1.3^{\mathrm{A}}$

$6.60 \pm 0.03^{B}$

$4.35 \pm 0.36^{A}$

$0.35 \pm 0.1^{B}$

$0.08 \pm 0.01^{A}$

$0.68 \pm 0.03^{\mathrm{A}}$

$0.23 \pm 0.05^{B}$

$0.13 \pm 0.01^{A}$
FEMALES

SD diet

$8.56 \pm 0.51^{\mathrm{a}}$

$3.11 \pm 0.13^{A}$

$5.96 \pm 0.36^{\mathrm{a}}$

$2.19 \pm 0.18^{\circ}$

HF diet

$8.14 \pm 0.21^{\mathrm{a}}$

CAF diet

$8.16 \pm 0.24^{\mathrm{a}}$

$2.81 \pm 0.05^{a}$

$4.87 \pm 0.13^{c}$

$1.78 \pm 0.09^{a b}$

$3.89 \pm 0.09^{b}$

$11.0 \pm 0.9^{b}$

$3.78 \pm 0.24^{b}$

$6.10 \pm 0.52^{\mathrm{c}}$

$2.10 \pm 0.14^{a c}$

$5.94 \pm 0.53^{\mathrm{a}}$

$2.05 \pm 0.13^{a b}$

$23.1 \pm 1.8^{\mathrm{b}}$

$7.93 \pm 0.43^{b}$

$0.60 \pm 0.04^{\mathrm{a}}$

$0.18 \pm 0.03^{a b} \quad 0.21 \pm 0.02^{a}$
ANOVA

HP diet

$7.66 \pm 0.37^{\mathrm{a}}$ DS

$3.16 \pm 0.01^{a} \quad D S$

$4.79 \pm 0.22^{\mathrm{bc}}$ D S

$1.87 \pm 0.07^{a} \quad D S$

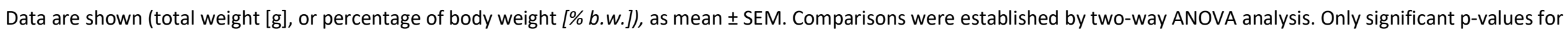

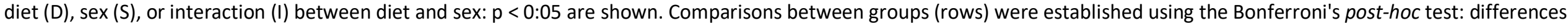
between groups are represented by different superscript letters (low case letters for females and capital letters for males). 